\title{
Anti-ulcer Effect of Gastroretentive Drug Delivery System of Alginate Beads Containing Turmeric Extract Solid Dispersion
}

\author{
Hakim Bangun*, Anayanti Arianto, Elfina Rehngenana \\ Department of Pharmaceutical Technology, Faculty of Pharmacy, Nanomedicine Centre, Universitas Sumatera Utara, Jl. Tri \\ Dharma No. 5, Kampus USU, Medan, Indonesia
}

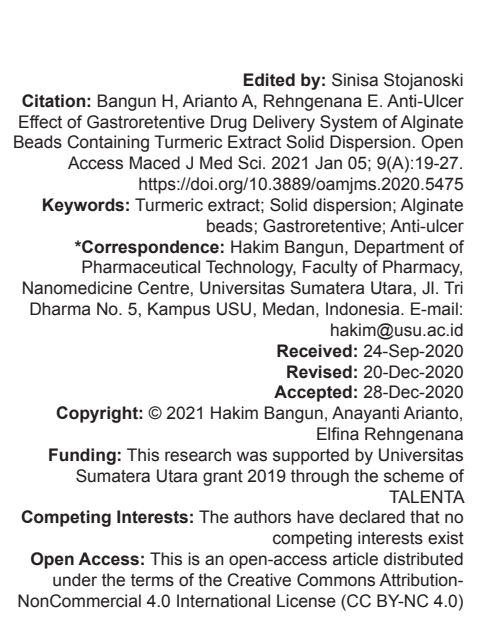

\section{Introduction}

Peptic ulcer is a disease due to disorders of the upper gastrointestinal tract caused by the by excessive of acid and pepsin secretion [1]. Peptic ulcers can occur due to an imbalance between aggressive factors (such as Helicobacter pylori infection, nonsteroidal antiinflammatory drugs [NSAIDs], and stomach acid) and stomach defensive factors (such as mucin, bicarbonate, and prostaglandins) resulting in damage of the gastric mucosa [2]. The systemic prostaglandin inhibition due to the use of NSAIDs causes the decrease of epithelial mucus secretion, mucosal blood flow, epithelial cell proliferation, bicarbonate secretion, and mucosal resistance to injury; and the presence of gastric acid plays a critical role in mucosal damage [3].

Turmeric (Curcuma longa Linn or Curcuma domestica Val.), including the family of Zingibraceae, contains curcumin which is has been known by the community as a plant that has many benefits such as anti-inflammatory [4], anticancer [5], antioxidants [6], antiulcer [7], and antibacterial agents [8]. However, its pharmacological effects are limited due to low solubility and instability in alkaline $\mathrm{pH}$ of intestine $\mathrm{pH}$ [9], [10].

Solid dispersion is defined as dispersion of one or more active ingredients (hydrophobic) in an inert carrier (hydrophilic) at solid state prepared by melting (fusion), solvent or melting solvent method [11]. Preparation of solid dispersion with hydrophilic polymers is an effective way of improving the dissolution of pure solubility of the drug. The gastroretentive drug delivery system is an approach to prolong the gastric residence time, thereby targeting a site specific drug release in the stomach for local or systemic effect and gastroretentive drug delivery systems is suitable for unstable drugs at alkaline $\mathrm{pH}$ [12].

Turmeric extract is an alcohol extract from turmeric powder. Our previous study showed the antiulcer activity of gastroretentive drug delivery system of alginate beads containing turmeric extract [13]. The dissolution of curcumin and the antibacterial activity is higher in alginate beads containing turmeric extract solid dispersion than alginate beads containing turmeric extract [14].

Alginate is a negatively charged polysaccharide which is non-toxic, biocompatible, 
and biodegradable. It is an anionic bioadhesive polymer, forming hydrogen bonds with hydroxyl group of polysaccharide chain in mucous glycoprotein and its chemical bond was non-covalent [15]. Previous study also reported the bioadhesive properties of alginate beads [16], [17]. Alginate interacts with organic diacidic base piperazine and calcium salts [18]. Lamivudine sodium alginate beads which were prepared by the ionotropic gelation method showed prolonged drug release $(\sim 12 \mathrm{~h})$ and the release was controlled by diffusion from alginate beads that were slow and spreads over an extended period of time depending on the drug polymer ratio [19].

In this study, an approach to improve the antiulcer effect of turmeric extract is by converting turmeric extract to turmeric extract solid dispersion to increase the dissolution of curcumin. Then, the preparation was made as gastroretentive drug delivery system using alginate beads to increase the absorption of curcumin. Alginate beads are a mucoadhesive gastroretentive drug delivery system [16], [17]. It might be useful to prolong the residence time of preparation in the stomach so that increases the drug absorption.

In this paper will be discussed the anti-ulcer effect of alginate beads containing turmeric extract solid dispersion compared to alginate beads containing turmeric extract and negative control.

\section{Materials and Methods}

\section{Materials}

The material used in this research was turmeric rhizome obtained from the Medan Central Market, Indonesia. The material was processed to turmeric extract in laboratory of phytochemistry of our faculty. Water content of turmeric extract was $8.36 \%$, ethanol soluble extract content was $20.81 \%$, water soluble extract content was $17.31 \%$, total was ash was $7.18 \%$, and acid insoluble content was $0.44 \%$. Ethanol and Tween 80 obtained from Brataco (Indonesia). Polyvinylpyrrolidone (PVP) K30 was a product of Nacalai Tesque. Calcium chloride and hydrochloric acid were product of Merck. Sodium alginate was the product of Wako Pure Chemical Industries, Ltd., Japan, for animal studies used white rats (Rattus norvegicus) weighing 180-200 g.

\section{Identification of plant material}

Identification of plant material (rhizome) was done in the Herbarium Medanense (MEDA), University of Sumatera Utara, Medan.

\section{Preparation of turmeric extract}

Turmeric powder was macerated with ethanol $96 \%$ for 8 days. Then, the macerate was evaporated with a rotary evaporator at $50^{\circ} \mathrm{C}$ and 100 mbar to obtain the concentrated turmeric extract.

\section{Preparation of solid dispersion}

Turmeric extract-PVP solid dispersion was prepared by solvent method. The ratio of turmeric extract and PVP was 1:1. Turmeric extract and PVP were dissolved in ethanol. Then, ethanol was evaporated. The resulting turmeric extract-PVP solid dispersion was scraped and then sifted using a sieve No. 12.

\section{Preparation of alginate beads containing turmeric extract/turmeric extracts solid dispersion}

Sodium alginate solution was prepared by adding sodium alginate $(1.5 \% \mathrm{w} / \mathrm{v})$ in distilled water. Turmeric extract or turmeric solid-PVP solid dispersion was crushed with the addition of ethanol until dissolved and it was mixed with Tween 80 , then added into the alginate solution and stirred until the mixture became homogenous. Then, the mixture was dropped wise through a syringe of $21 \mathrm{G}$ size into $0.15 \mathrm{M}$ calcium chloride solution with curing time 4-5 $\mathrm{min}$ [14]. Then, the beads formed were separated from the solution by filtration and rinsed with distilled water. Finally, the beads containing turmeric extract/turmeric extract solid dispersion were dried at room temperature and stored in a desiccator. The formula used is shown in Table 1. Two milliliters of the mixture produced 20 beads. Theoretically, each bead contained $5 \mathrm{mg}$ turmeric extract or $10 \mathrm{mg}$ turmeric extract solid dispersion (equivalent to $5 \mathrm{mg}$ turmeric extract). Photo of alginate beads containing turmeric extract solid dispersion is shown in Figure 1.

Table 1: Formula of alginate beads containing turmeric extract/ turmeric extract solid dispersion

\begin{tabular}{llll}
\hline Materials & F1 & F2 & F3 \\
\hline Sodium alginate & $0.75 \mathrm{~g}$ & $0.75 \mathrm{~g}$ & $0.75 \mathrm{~g}$ \\
PVP & $7.5 \mathrm{~g}$ & - & - \\
Turmeric extract & $7.5 \mathrm{~g}$ & - & \\
Turmeric extract solid dispersion & - & - & $15 \mathrm{~g}$ \\
Tween 80 & - & $0.75 \mathrm{~g}$ & $0.75 \mathrm{~g}$ \\
Distilled water & & & \\
\hline F1: Contained only PVP (negative control). F2: Contained 7.5 g turmeric extract. F3: Contained 15 g
\end{tabular}

\section{In vivo gastroretentive properties test} alginate beads containing turmeric extract solid dispersion

Before the experiment, the animals were maintained in standard animal house for 2 weeks and given standard pellet diets and tap water ad libitum. The rats were fasted from all medications at least 2 weeks before the tests were done. All of the rats adhered to standard operation procedure and approved by Animal Research 


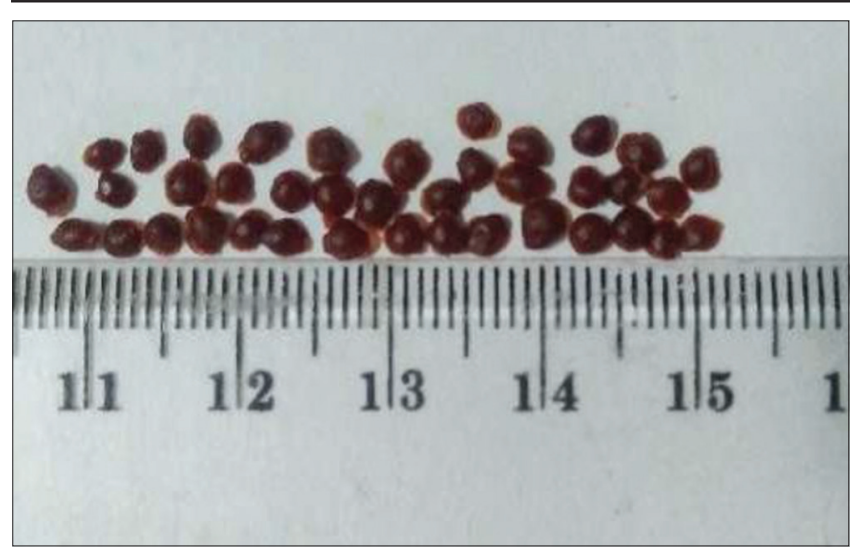

Figure 1: Photo of alginate beads containing turmeric extract solid dispersion (turmeric extract- polyvinylpyrrolidone). The diameter of beads was about $1.5 \mathrm{~mm}$

Ethics Committee/AREC No. 0481/KEPH-FMIPA/2019 of Faculty of Mathematics and Natural Sciences, Universitas Sumatera Utara. For int vivo gastroretentive study, three rats were fasted for $24 \mathrm{~h}$. Then, each rat was given three alginate beads containing turmeric solid dispersion. After $12 \mathrm{~h}$, the rats were sacrificed by ether inhalation and the stomachs were dissected to observe the remained beads in the stomachs.

\section{Induction of rat gastric ulcers with $0.6 \mathrm{~N}$ $\mathrm{HCl}$ and treatment of gastric ulcers}

Thirty-nine rats were fasted for $36 \mathrm{~h}$. Then, all rats were given $1 \mathrm{ml}$ of $0.6 \mathrm{~N} \mathrm{HCL}$ solutions orally to induce the gastric ulcer in rats. After $1 \mathrm{~h}$, three rats were sacrificed by ether inhalation and their stomach was dissected and washed with saline and then observed the stomach condition macroscopically (number of ulcers and ulcer index) and microscopic (histopathology). The stomach condition of the rats after being induced by $0.6 \mathrm{~N} \mathrm{HCL}$ was considered as the initial condition of gastric damage to the rats.

The remaining rats (36 rats) were divided in three groups; each group was consisted of 12 rats.

Group 1 (F1): Negative control, given alginate beads (3-4 beads) without turmeric extract (only containing PVP) once a day for 8 days.

Group 2 (F2): Given alginate beads (3-4 beads) containing turmeric extract at a dose of $100 \mathrm{mg} /$ $\mathrm{kg}$ body weight once a day for 8 days.

Group 3 (F3): Given alginate beads containing turmeric extract solid dispersion at an equivalent dose of turmeric extract of $100 \mathrm{mg} / \mathrm{kg}$ body weight (3-4 beads) once a day for 8 days.

Then, three rats of each group were scarified at $2^{\text {nd }}, 4^{\text {th }}, 6^{\text {th }}$, and $8^{\text {th }}$ days by inhalation using diethyl ether. The stomachs were dissected to observe the stomach condition macroscopically and microscopically. For microscopic observation, the gastric mucosa was immersed in $10 \%$ formalin for histopathology processing with hematoxylin-eosin staining and observed using a microscope. In this experiment, the macroscopic parameter used was number ulcer index, while the microscopic parameter was described as histologic score.

The calculation of the ulcer index used the following formula [20]:

$$
\text { Ulcer Index }=\frac{\text { Width of the ulcer }}{\text { Total width of stomach }} \times 100
$$

The histologic score was described as follows:

0 : Normal mucosa

1: Erosion of epithelial cells

2: Erosion of epithelial cells and lamina propria

3: Erosion until muscularis mucosa

4: Erosion until sub mucosa

\section{Statistically analysis}

Statistically analysis of antiulcer effect was performed using one-way analysis of variance (ANOVA) using SPSS 23.

\section{Results}

\section{Gastroretentive properties of alginate beads}

Twelve hours after the administration of alginate beads containing turmeric solid dispersion, the beads were still remaining in the stomach as shown in Figure 2. The beads attached to gastric mucosa due the mucoadhesive properties of alginate, resulting the gastroretentive properties of alginate beads. The beads were still in the stomach $12 \mathrm{~h}$ after oral administration.

\section{solution}

\section{Gastric ulcer induction with 0.6 N HCL}

Gastric ulcer induction with $0.6 \mathrm{HCl}$ solution caused ulcer and gastric bleeding in rats. Macroscopic pictures are shown in Figure 3a. The average ulcer number was $11.67 \pm 0.58$ (Table 2 ) and ulcer index was $5.65 \pm 0.04$ (Table 2). The induction of rat stomach with $0.6 \mathrm{~N} \mathrm{HCl}$ caused the damage of rat stomach as

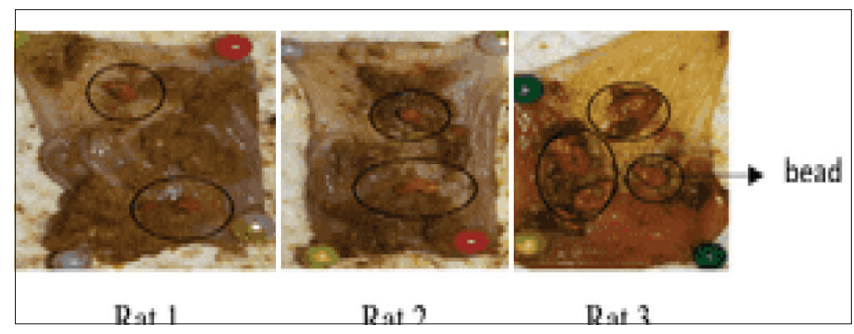

Figure 2: Alginate beads containing turmeric extract solid dispersion were still in the stomach $12 \mathrm{~h}$ after oral administration 


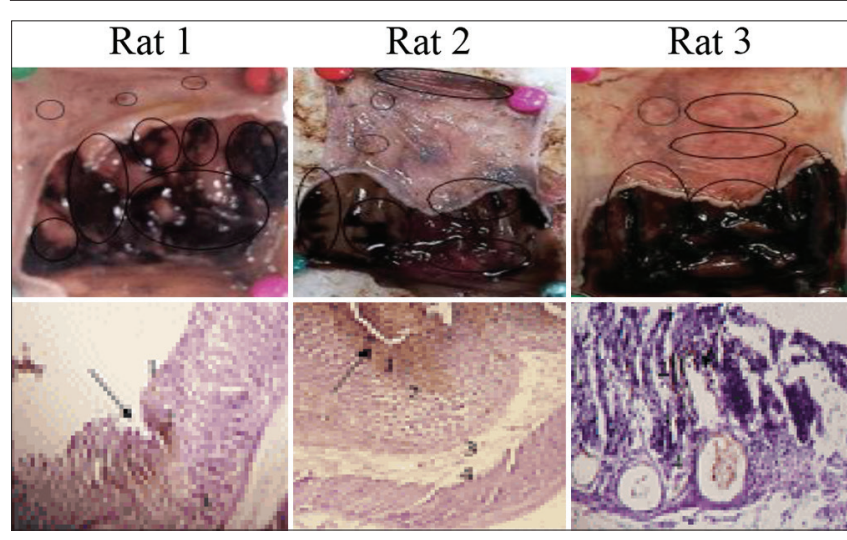

Figure 3: Macroscopic and microscopic pictures of rat stomach after induction with 0.6 N HCL solution (a). Macroscopic pictures of stomachs; (b). Microscopic pictures of stomachs. 1. Epithelial cells, 2. Lamina propria, 3. Muscularis mucosa, and 4. Submucosa

shown in Figure 3. The average of histological score was $2.33 \pm 0.58$ (Figure 8 ). It means that the damage of stomachs mucosa due to administration of $\mathrm{HCl}$ solution was included epithelial cells, lamina propria, and muscularis mucosa as shown in Figure 3b. This condition was thought as the initial condition of stomach ulcer before the treatment.

Table 2: The average ulcer index of rat stomach during the treatment with various formulation

\begin{tabular}{llll}
\hline Day & \multicolumn{3}{l}{ Average ulcer index $(\mathrm{X} \pm \mathrm{SD})$} \\
\cline { 2 - 4 } & $\begin{array}{l}\text { Beads alginate containing } \\
\text { PVP }\end{array}$ & $\begin{array}{l}\text { Beads alginate } \\
\text { containing turmeric } \\
\text { (negative control) }(\mathrm{F} 1)\end{array}$ & $\begin{array}{l}\text { Beads alginate containing } \\
\text { turmeric extract solid } \\
\text { dispersion }(\mathrm{F} 3)\end{array}$ \\
\hline 0 & $5.65 \pm 0.04$ & $5.65 \pm 0.04$ & $5.65 \pm 0.04$ \\
2 & $1.98 \pm 1.03$ & $1.05 \pm 0.72$ & $0.57 \pm 0.92$ \\
4 & $1.37 \pm 0.45$ & $0.12 \pm 0.17$ & $0.00 \pm 0.00$ \\
6 & $0.12 \pm 0.03$ & $0.03 \pm 0.03$ & $0.00 \pm 000$ \\
8 & $0.00 \pm 00$ & $0.00 \pm 0.00$ & $0.00 \pm 0.00$ \\
\hline PVP: Polyvinylpyrrolidone. & &
\end{tabular}

\section{Treatment of gastric ulcer}

After 2 days

Negative control

After 2 days, the macroscopic pictures of stomachs are shown in Figure $4 \mathrm{~A}(\mathrm{a})$. The ulcer index was $1.98 \pm 1.03$ (Table 2). The microscopic pictures of the stomach tissue of rats are shown in Figure $4 \mathrm{~A}(\mathrm{~b})$. The average histological score was 2.00 (Figure 8). This means the damage to gastric mucosa due to erosion of epithelial cells and lamina propria.

\section{Alginate beads containing turmeric extract}

After 2 days of treatment with alginate beads containing turmeric extract, the macroscopic pictures of rat's stomachs are shown in Figure 4 B (a). The ulcer index was $1.05 \pm 0.72$ (Table 2). The microscopic pictures are shown in Figure $4 \mathrm{~B}$ (b). The average histological score was $1.67 \pm 0.58$ (Figure 8). This means the erosion of epithelial cells and lamina propria of gastric mucosa.

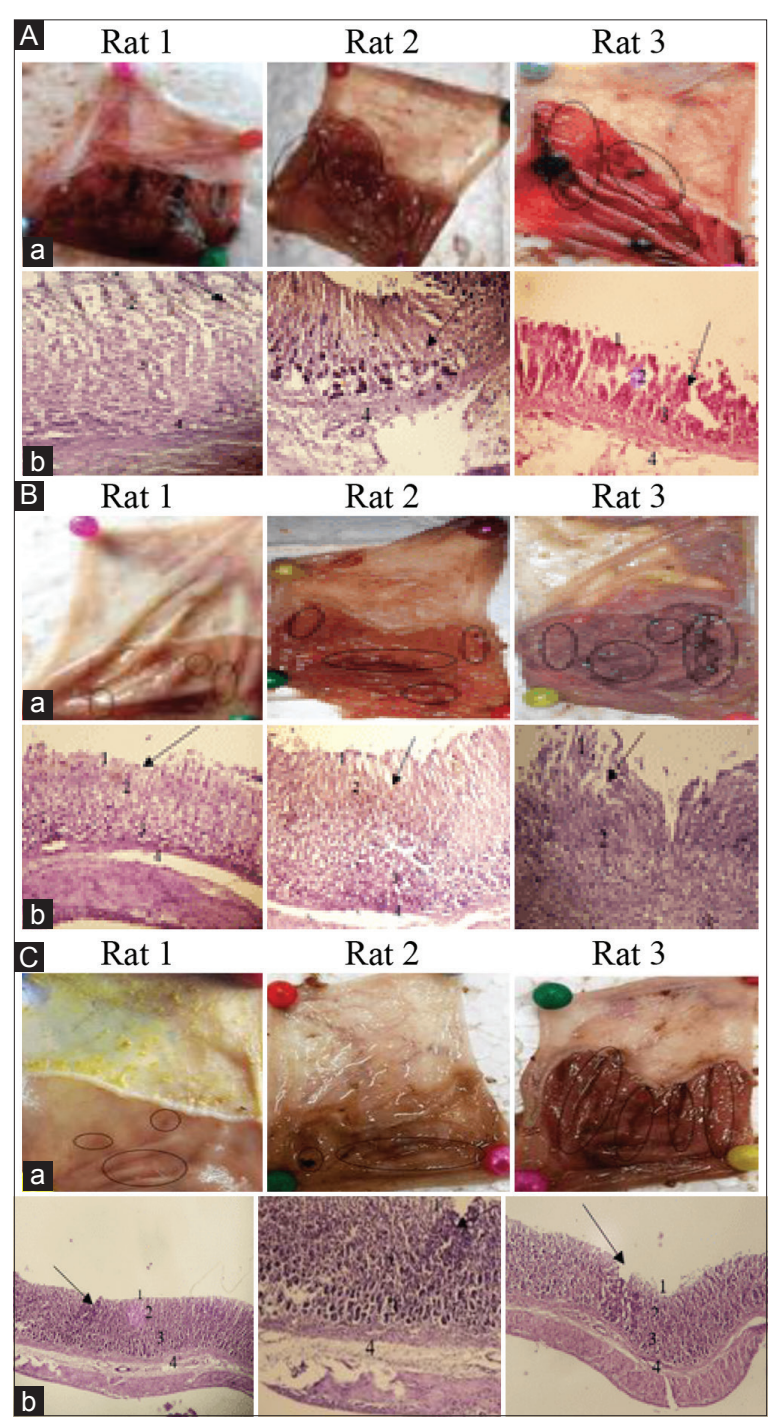

Figure 4: Macroscopic and microscopic pictures of rat stomach after 2 days of treatment. A. Negative control; B. Treatment with alginate beads containing turmeric extract; $C$. Treatment with alginate beads containing turmeric extract solid dispersion. (a) Macroscopic of stomach; (b) microscopic of stomach. 1. Epithelial cells, 2. Lamina propria, 3. Muscularis mucosa, and 4. Submucosa

Alginate beads containing turmeric extract solid dispersion

The macroscopic pictures of rat stomach after 2 days of treatment with alginate beads containing turmeric extract solid dispersion are shown in Figure 4 C (a). The ulcer index was $0.57 \pm 0.92$ (Table 2). The microscopic pictures are shown in Figure $4 \mathrm{C} \mathrm{(b).} \mathrm{The}$ average histological score was $0.67 \pm 0.58$ (Figure 8). This means the erosion of epithelial cell area and slightly in lamina propria of gastric mucosa.

\section{After 4 days}

Negative control

After 4 days, the macroscopic pictures are shown in Figure $5 \mathrm{~A}$ (a). The average ulcer index was $1.37 \pm 0.45$ (Table 2). The microscopic pictures of the stomach tissue of rats are shown in Figure $5 \mathrm{~A}(\mathrm{~b})$. The 
average histological score was 2.00 (Figure 8). This means the erosion of epithelial cells and lamina propria of gastric mucosa.

\section{Alginate beads containing turmeric extract}

After 4 days of treatment with alginate beads containing turmeric extract, the macroscopic pictures of stomach are shown Figure $5 \mathrm{~B}$ (a). The ulcer index was $0.12 \pm 0.17$ (Table 2). The microscopic pictures are shown in Figure $5 \mathrm{~B}$ (b). The average histological score was 1.00 (Figure 8). This means the erosion only in the epithelial cells of the gastric mucosa.

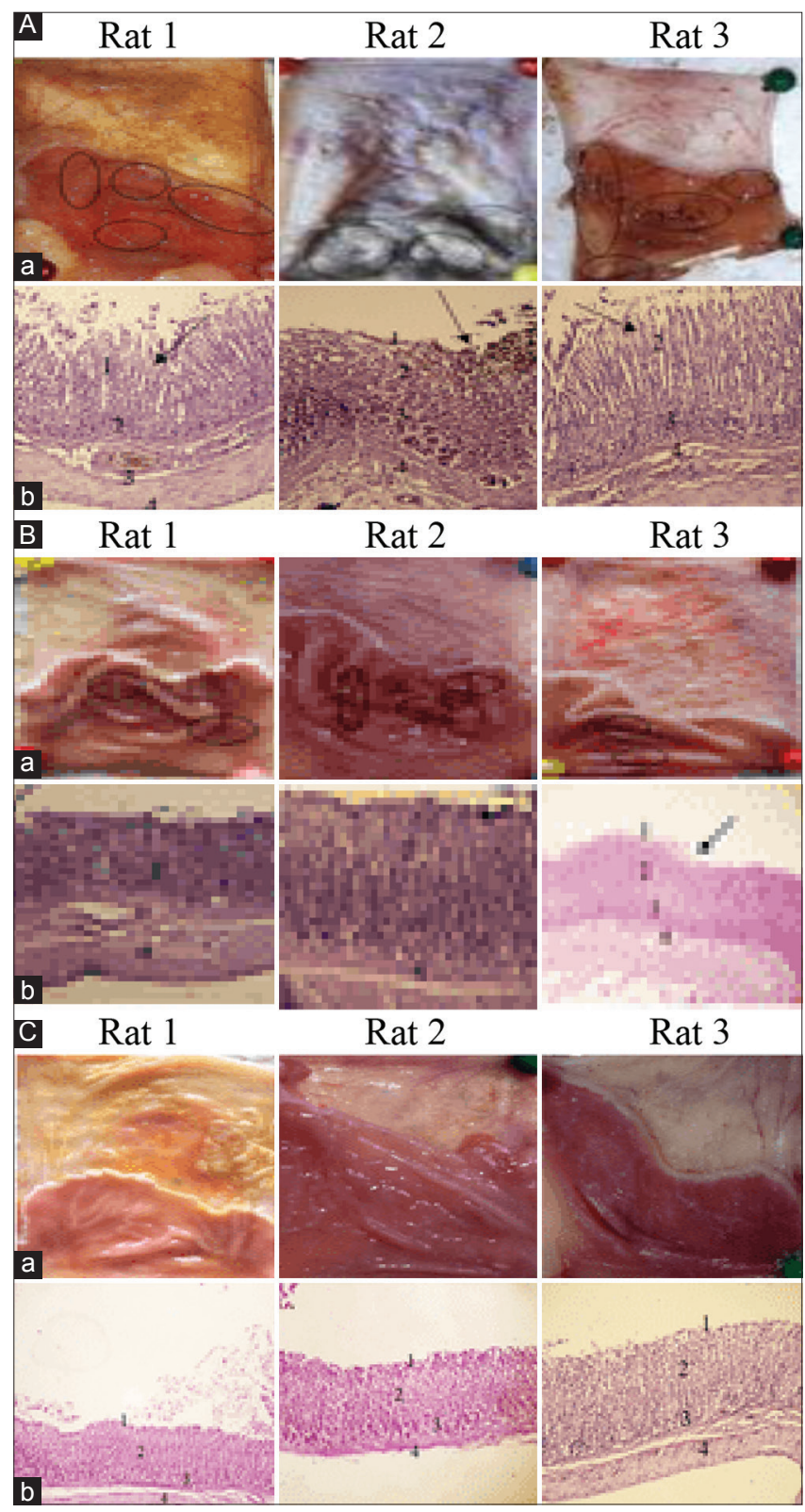

Figure 5: Macroscopic and microscopic pictures of rat stomach after 4 days treatment. A. Negative control; $B$. Treatment with alginate beads containing turmeric extract; $C$. Treatment with alginate beads containing turmeric extract solid dispersion. (a) Macroscopic of stomach; (b) microscopic of stomach. 1. Epithelial cells, 2. Lamina propria, 3. Muscularis mucosa, and 4. Submucosa
Alginate beads containing turmeric extract solid dispersion

The macroscopic pictures of rat stomach after 4 days treatment with alginate beads containing turmeric extract solid dispersion are shown in Figure $5 \mathrm{C}$ (a). The ulcer index was zero (Table 3). The microscopic pictures are shown in Figure $5 \mathrm{C}$ (b). The average histological score was zero (Figure 8). The index was zero. This means that the ulcer was not visible. The histological score was also zero. This means that the ulcers were healed after 4 days treatment with alginate beads containing turmeric solid dispersion.

\section{After 6 days}

Negative control

After 6 days, the macroscopic pictures are shown in Figure $6 \mathrm{~A}(\mathrm{a})$. The ulcer index was $0.12 \pm$ 0.03 (Table 2). The microscopic pictures of the stomach tissue of rats are shown in Figure $6 \mathrm{~A}(\mathrm{~b})$. The average histological score was $1.67 \pm 0.58$ (Figure 8). This means the erosion of epithelial cells and lamina propria of gastric mucosa.

\section{Alginate beads containing turmeric extract}

After 6 days of treatment with alginate beads containing turmeric extract, the macroscopic pictures of rat stomach are shown in Figure $6 \mathrm{~B}$ (a) and the microscopic pictures are shown in Figure $6 \mathrm{~B}$ (b). The ulcer index was $0.03 \pm 0.03$ (Table 2). The average histological score was $0.67 \pm 0.58$ (Figure 8). This means the erosion of epithelial cells only of gastric mucosa.

\section{Alginate beads containing turmeric solid dispersion}

Although the ulcers were healed after 4 days treatment with alginate beads containing turmeric extract solid dispersion, the treatment was continued with alginate beads containing turmeric extract solid dispersion until 8 days as in other group. The macroscopic picture of rat stomach after treatment 6 days with alginate beads containing turmeric extract solid dispersion is shown in Figure $6 \mathrm{C} \mathrm{(a)}$ and the microscopic picture is shown in Figure $6 \mathrm{C}$ (b). The ulcer index was zero (Table 2). The average histological score was zero (Figure 8).

\section{After 8 days}

\section{Negative control}

After 8 days, the macroscopic pictures are shown in Figure $7 \mathrm{~A}$ (a) and microscopic pictures of the stomach tissue of rats are shown in Figure $7 \mathrm{~A}$ (b). The ulcer index was zero (Table 2) and the average 

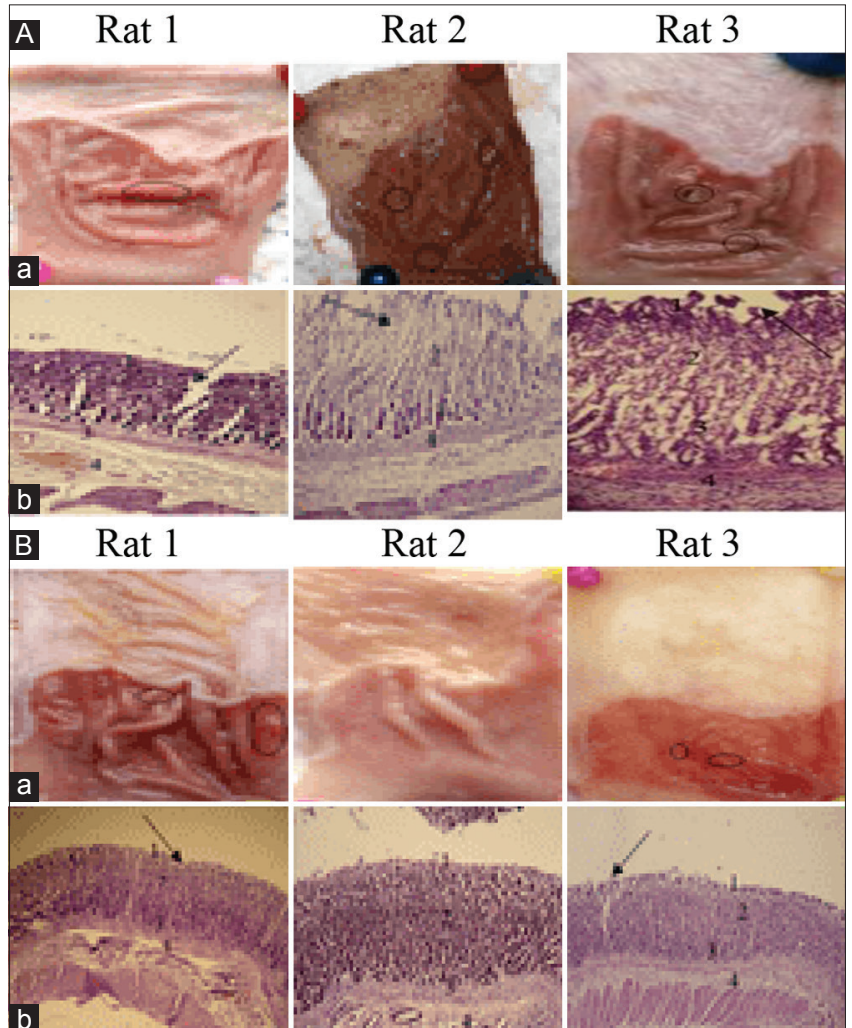

Rat 3

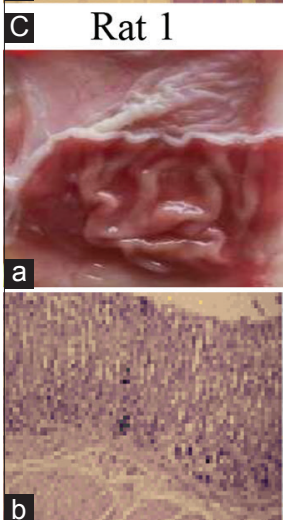

Rat 2

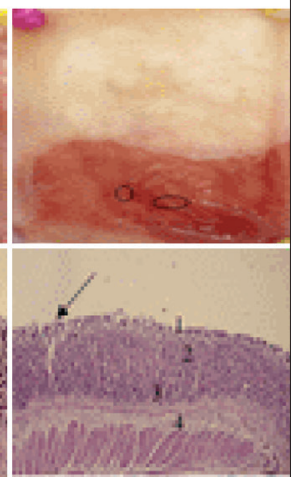

Rat 3
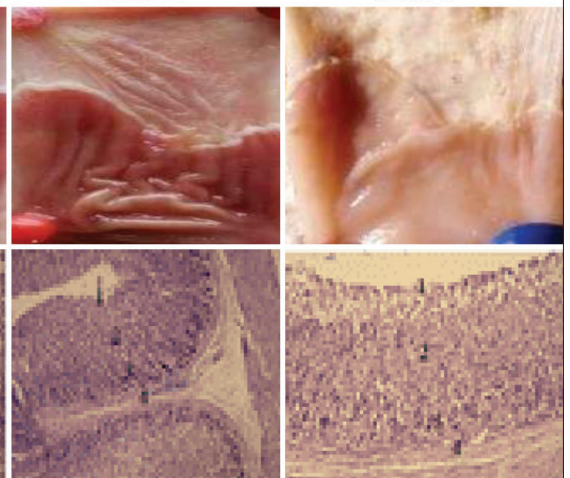

Figure 6: Macroscopic and microscopic pictures of rat stomach after 6 days treatment. A. Negative control; B. Treatment with alginate beads containing turmeric extract.; C. Treatment with alginate beads containing turmeric extract solid dispersion; (a). Macroscopic of stomachs; (b) microscopic of stomach; 1. Epithelial cells; 2. Lamina propria; 3. Muscularis mucosa; 4. Submucosa

histological score was $0.67 \pm 0.58$ (Figure 8). This means after 8 days, macroscopically the ulcers were not visible, but microscopically had not healed. There was still the erosion of epithelial cells of gastric mucosa.

Alginate beads containing turmeric extract

After 8 days treatment with alginate beads containing turmeric extract, the macroscopic pictures of rat stomach are shown in Figure $7 \mathrm{~B}$ (a) and the microscopic pictures are shown in Figure 7 B (b). The ulcer index was zero (Table 2). The average histological score was also zero (Figure 8). This means that the ulcers were healed after 8 days treatment with alginate beads containing turmeric extract.
Alginate beads containing turmeric extract solid dispersion

The macroscopic pictures of rat stomach after treatment 8 days with alginate beads containing turmeric extract solid dispersion are shown in Figure $7 \mathrm{C}$ (a) and the microscopic pictures are shown in Figure 7 C (b). The ulcer index was zero (Table 2) and the histological score was zero (Figure 8). The treatment for 6 and 8 days gave the same results as the treatment for 4 days. This means that the ulcers were completely healed after for 4 days treatment with alginate beads containing turmeric solid dispersion.

Statistically analysis of ulcer index (Table 2) by One-Way ANOVA showed that there was a significant different $(p<0.05)$ since the $4^{\text {th }}$ day between control negative group (F1) and alginate beads containing 


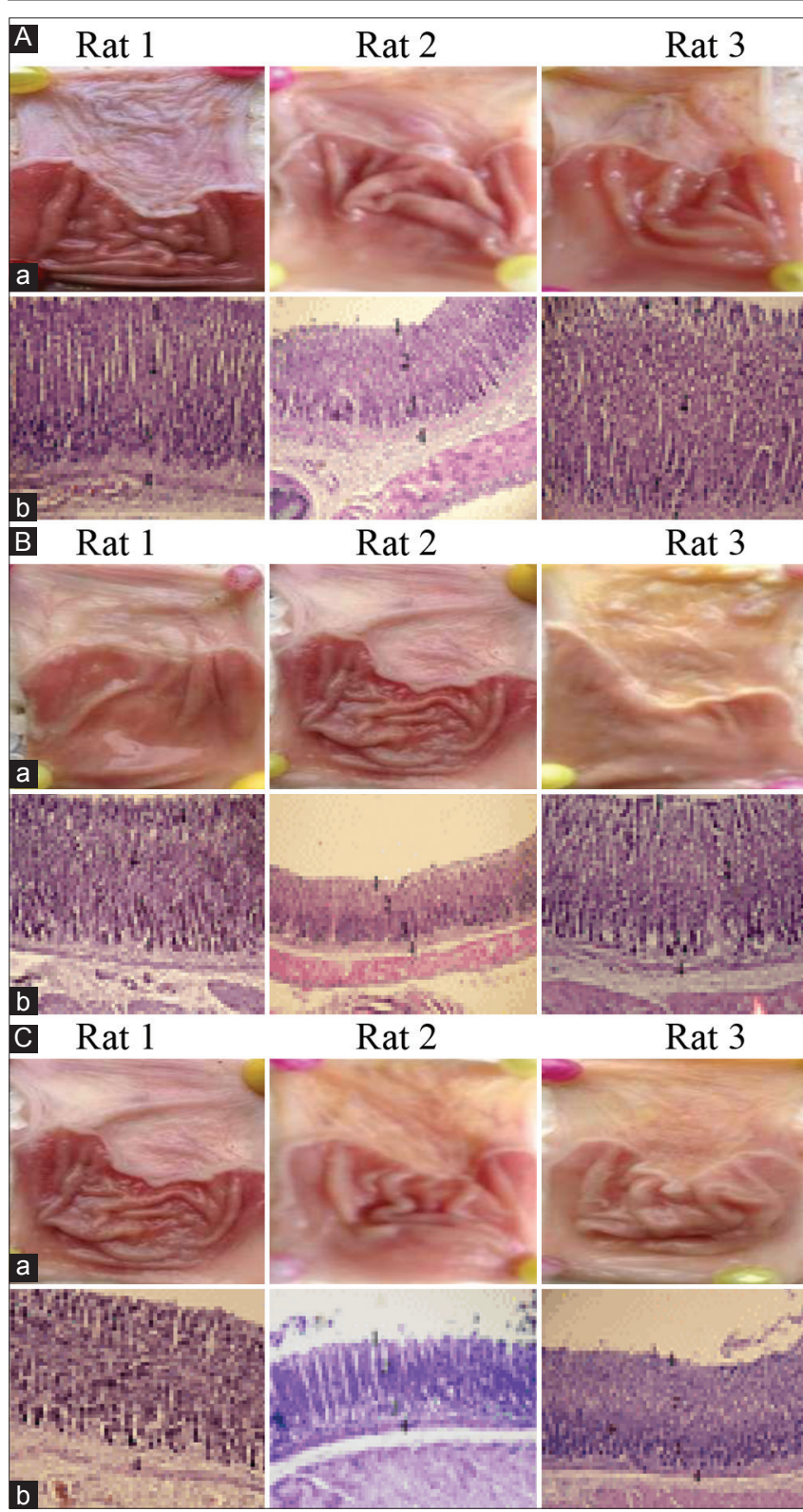

Figure 7: Macroscopic and microscopic pictures of rat stomach after 8 days treatment. A. Negative control; B. Treatment with alginate beads containing turmeric extract; $C$. Treatment with alginate beads containing turmeric extract solid dispersion; (a). Macroscopic of stomachs; (b) microscopic of stomach; 1. Epithelial cells, 2. Lamina propria, 3. Muscularis mucosa, 4. Submucosa

turmeric extract (F2) and solid dispersion group of rats (F3). However, between alginate beads containing turmeric extract (F2) and alginate beads containing turmeric extract solid dispersion showed no significant different $(p>0.05)$.

Statistically analysis of histologically score of data is shown in Figure 8 by One-Way ANOVA showed that there was a significant different $(p<0.05)$ since the $6^{\text {th }}$ day between negative control (F1) and alginate beads containing turmeric extract (F2) and there was a significant different $(p<0.05)$ since the $4^{\text {th }}$ day between negative control (F1) and alginate beads containing turmeric solid dispersion (F3). However, there was no significant different $(p>0.05)$ between alginate beads containing turmeric extract (F2) and alginate beads containing turmeric extract solid dispersion (F3).

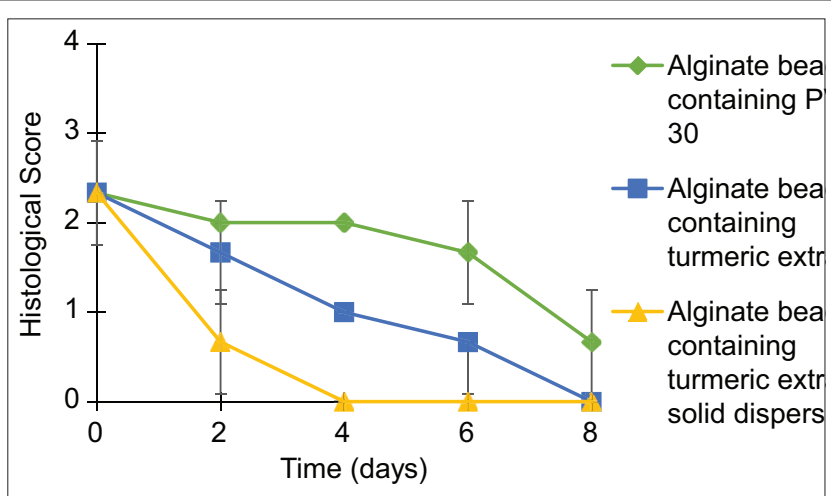

Figure 8: The graph of histological score against length of treatment with various formulation

\section{Discussion}

In this experiment, the turmeric extract-PVP solid dispersion was prepared by the solvent method using PVP as a carrier [19]. The purpose of making turmeric extract solid dispersion was to increase the dissolution of curcumin. Previous studies showed that the curcumin amount released in simulated gastric fluid of $\mathrm{pH} 1.2$ was higher from turmeric extract-PVP solid dispersion compared to from turmeric extract without solid dispersion. Another study using the active ingredient curcumin showed the solid dispersion of curcumin-PVP increased the dissolution of curcumin [21].

The use of PVP as water-soluble polymer in the preparation of turmeric extract solid dispersion enhances the wetting process of curcumin. In addition, the conversion of turmeric extract to turmeric solid dispersion might reduce the particle size of curcumin. Therefore, conversion of turmeric extract to turmeric extract solid dispersion causes faster dissolution of curcumin [14]. The faster dissolution of curcumin in turmeric solid dispersion that causes alginate beads containing turmeric extract is more effective as an antiulcer than alginate beads containing turmeric extract.

The mucoadhesive properties of alginate beads have been previously reported [12], [16], [17] The mucosa lining of the stomach is rich in mucin, which contain an oligosaccharide chain with terminal sialic acid. Polyanions, especially polymer bearing carboxylic groups and high charge density, serve as powerful "ligands" for mucin and are called mucoadhesive polymers, for example, alginate [22]. The formation of hydrogen-bonds among the functional groups of the polymer mucus layer also plays an important role. In general, the stronger the hydrogen bond, the stronger the adhesion. The functional groups responsible for such kind of interaction are carboxyl, hydroxyl, and amine groups. Alginate contains carboxyl and hydroxyl groups [23].

Gastric mucosa has a special barrier against noxious agents such as $\mathrm{HCl}$. As a barrier, sodium bicarbonate is secreted from the surface of epithelial 
cells of gastric mucosa and incorporate into the mucus layer. This mucus layer containing sodium bicarbonate may play a role in the mucosal barrier against gastric acid. When the mucosal barrier is broken by the excessive of $\mathrm{HCl}$, then allows a back diffusion of gastric acid into the mucosal cells, leading to mucosal damage [24]. The induction of rat stomach with $0.6 \mathrm{~N}$ $\mathrm{HCl}$ caused the damage of rat stomach, as shown in Figure 3. The damage of stomachs was until muscularis mucosa was due to the excessive of $\mathrm{HCl}$.

Based on statistically analysis of the histological score by One-Way ANOVA as mentioned above, since the $6^{\text {th }}$ day after treatment there was a significant different $(p=0.05)$ the antiulcer effect between alginate beads containing turmeric extract and negative control. Alginate beads containing turmeric extract solid dispersion were more effective. Since the $4^{\text {th }}$ after treatment there was a significant different $(p<0.05)$ between alginate beads containing turmeric solid dispersion and negative control as shown in Figure 8. Alginate beads containing turmeric extract solid dispersion were more effective as antiulcer than alginate beads containing turmeric extract, but statistically it was not significant different $(p>0.05)$, as shown in Figure 8.

Healing of peptic ulcers requires rearrangement of epithelial structures and the connective tissues, including the lining of the vessels and muscles. Several growth factors have been involved in this process, because of their ability to regulate important cell functions, such as cell proliferation, migration, differentiation, secretion, and extracellular matrix degradation, where everything is important during tissue healing [25].

In animal study, curcumin solid dispersion has anti-gastric ulcer effects by inhibiting gastric acid secretion, reducing gastric juice acidity, inhibiting the activity of pepsin and promoting healing of ulcer [26]. Our study showed that the stomach $\mathrm{pH}$ increased from 2.3 to 3.3 after 1 day and raised to 5.3 after 4 days treatment using alginate beads containing turmeric extract solid dispersion. The data are not presented here. Curcuma longa extract (turmeric extract) inhibits gastric acid secretion by blocking $(\mathrm{H} 2)$ histamine receptors in a competitive manner [27]. Stomach ulcer healing occurs when the $\mathrm{pH}$ is maintained above 3-4 [28]. Another study shows that the antiulcer activity of curcumin was displayed by attenuating the different ulcerative effectors including gastric acid hyper-secretion, total peroxides, myeloperoxidase activity, Interleukin-6, and apoptotic incidence, along with its inhibitory activity in pepsin [29].

To increase the information about the antiulcer effect of gastroretentive drug delivery system of alginate beads containing turmeric extract needs to be compared the antiulcer effect to drug of choice such as protonpump inhibitors in the future or more studies regarding the superiority of gastroretentive drug delivery system are mandatory.

\section{Conclusion}

Gastroretentive drug delivery system of alginate beads containing turmeric extract solid dispersion is effective as an antiulcer in rats. These finding shows a potential application of alginate beads containing turmeric extract solid dispersion as an antiulcer. To get the complete information about its effectiveness, further research is needed such comparing its effectiveness with proton-pump inhibitors.

\section{Authors Contribution}

Hakim Bangun planned and designed all of the study, Anayanti Arianto supported the preparation of turmeric extract, and Elfina Rehngenana conducted the study.

\section{References}

1. Avunduk C. Manual of Gastroenterology: Diagnosis and Therapy. $4^{\text {th }}$ ed. USA: Lippincott Williams and Wilkins; 2008. p. $59-60$

2. Sunil K, Amandeep K, Robin S, Ramica S. Peptic ulcer: A review of etiology and pathogenesis. Int Res J Pharm. 2012;3(6):34-5.

3. Hunt RH, Yuan Y. Acid-NSAID/aspirin interaction in peptic ulcer disease. Dig Dis. 2011;29(5):465-8. https://doi. org/10.1159/000332211 PMid:22095011

4. Patil MB, Taralkar SV, Sakpal VS, Shewale SP, Sakpal RS. Extraction, isolation and evaluation of anti-inflammatory activity of curcuminoids from curcuma longa. Int J Chem Sci Appl. 2011;2(3):172-4

5. Naama JH, Al-Temini AA, Al-Amlery AA. Study the anticancer activities of ethanolic curcumin extract. Afr J Pure Appl Chem. 2011;4:68-73.

6. Tanvir EM, Hossen MS, Hossain MF, Afroz R, Gan SH, Khalil MI, et al. Antioxidant properties of popular turmeric (Curcuma longa) varieties from Bangladesh. J Food Qual. 2017;2017:1-8. https:// doi.org/10.1155/2017/8471785

7. Mahattanadul $S$, Nakamura $T$, Panichayupakaranant $P$, Phdoongsombut N, Tungsinmunkong K, Bouking P. Comparative antiulcer effect of bisdemethoxycurcumin and curcumin in a gastric ulcer model system. Phytomedicine. 2009;16:342-51. https://doi.org/10.1016/j.phymed.2008.12.005

PMid:19188055

8. Mohammed NA. Evaluation of antimicrobial activity of curcumin against two oral bacteria. Autom Control Intell Syst. 2015;3(2):18

9. Petchsomrit A, Sermkaew N, Wiwattanapatapee R. Effect of alginate and surfactant on physical properties of oil entrapped alginate bead formulation of curcumin. Int $\mathrm{J}$ Med Pharm Sci Eng. 2013;7(12):479-83. https://doi.org/10.3390/ scipharm85010011

10. Anand $P$, Kunnumakkara $A B$, Newman RA, Aggarwal $B B$. 
Bioavailability of curcumin: Problems and promises. Mol Pharm. 2007;4(6):807-18. https://doi.org/10.1021/mp700113r PMid:17999464

11. Chiou WL, Riegelman S. Pharmaceutical applications of solid dispersion systems. J Pharm Sci. 1971;60(9):1281-302. https:// doi.org/10.1002/jps.2600600902

PMid:4935981

12. Nayak KA, Maji R, Das B. Gastroretentive drug delivery systems: A review. Asian J Pharm Clin Res. 2010;3(1):1-10.

13. Bangun $H$, Aulia $F$, Arianto $A$, Nainggolan M. Preparation of mucoadhesive gastroretentive drug delivery system of alginate beads containing turmeric extract and anti-gastric ulcer activity. Asian J Pharm Clin Res. 2019;12(1):316. https://doi. org/10.22159/ajpcr.2018.v12i1.29715

14. Bangun $\mathrm{H}$, Arianto $\mathrm{A}$, Bangun $\mathrm{YS}$, Nainggolan M. Antibacterial activity of mucoadhesive gastroretentive drug delivery system of alginate beads containing turmeric extract-PVP solid dispersion. Open Access Maced J Med Sci. 2019;7(22):3868-73. https:// doi.org/10.3889/oamjms.2019.522 PMid:32127994

15. Vetter A, Schnurch AB. Bioadhesive Delivery Systems. Biodrug Delivery Systems: Fundamentals, Applications and Clinical Development. Boca Raton: CRC Press; 2010. p. 220-1. https:// doi.org/10.3109/9781420086713-16

16. Arianto $A$, Bangun $H$, Harahap $U$, llyas $S$. The comparison of swelling, mucoadhesive, and release of ranitidine from spherical matrices of alginate, chitosan, alginate-chitosan, and calcium alginate-chitosan. J Pharmtech Res. 2014;6(7):205463. Available from: http://sphinxsai.com/2014/ph_vol6 no7/2/(2054-2063)\%20ND14.pdf. https://doi.org/10.1016/j. ijpharm.2006.05.054

17. Arianto A, Bangun $H$, Harahap U, llyas S. Effect of alginate chitosan ratio on the swelling, mucoadhesive, and release of ranitidine from spherical matrices of alginate-chitosan. $J$ Pharmtech Res. 2015;8(4):653-65. Available from: http://www. sphinxsai.com/2015/ph_vol8_no4/1/(653-665)V8N4PT.pdf.

18. Kametani F, Bangun H, Ikeda $Y$, Shimabayashi S. Interaction of alginic acid with organic diacidic base piperazine. Chem Pharm Bull. 1990;38(10):2623-6. https://doi.org/10.1248/cpb.38.2623

19. Desi Reddy RB, Malleswari K, Prasad G, Prasanna D. Preparation and in vitro evaluation of lamivudine floating sodium alginate beads. Int J Pharm Clin Res. 2012;4(4):81-8.

20. Arianto $A$, Bangun $H$. Healing effect of alginate liquid against $\mathrm{HCl}$-induced gastric mucosal lesions in rats. Int $\mathrm{J}$ Pharmtech
Res. 2016;9(3):287-96. Available from: http://sphinxsai. com/2016/ph_vol9_no3/abstracts/A(287-296)V9N3PT.pdf.

21. Kaewnopparat N, Kaewnopparat S, Jangwang A, Maneenaun D, Chuchome T, Panicchayupakaranant P. Increased solubility, dissolution, and physicochemical studies of curcuminpolyvinylpyrrolidone K-30 solid dispersion. World Acad Sci Eng Technol. 2009;55:229-34.

22. Chikering D, Jacob J, Desai T, Harrison M, Harris W, Morrell C, et al. Bioadhesive microspheres: III. An in vivo transit and bioavailability study of drug-loaded alginate and poly (fumaric-co-sebacic anhydride) microspheres. J Control Release. 1997;48(1):35-46. https://doi.org/10.1016/ s0168-3659(97)00054-0

23. Haug A, Larsen B, Smidsrod O. A study of the constitution of alginic acid by partial acid hydrolysis. Acta Chem Scand. 1966;20:183. https://doi.org/10.3891/acta.chem.scand.20-0183

24. Price SA, Wilson LM. Pathophysiology: Clinical Concepts of Deseases Processes. $3^{\text {rd }}$ ed. New York: McGraw-Hill Book Company; 1986. p. 242-58.

25. Mani H, Sidhu GS, Kumari R, Gaddipati JP, Seth $P$, Maheshwari RK. Curcumin differentially regulates TGF-beta1, its receptors and nitric oxide synthase during impaired wound healing. Biofactors. 2002;16(1-2):29-43. https://doi.org/10.1002/ biof.5520160104

PMid: 12515914

26. Mei X, Xu D, Wang S, Xu S. Pharmacological researches of curcumin solid dispersions on experimental gastric ulcer. Zhongguo Zhong Yao Za Zhi. 2009;34(22):2920-3.

PMid:20209961

27. Kim DC, Kim SH, Choi BH, Baek NI, Kim D, Kim MJ, et al. Curcuma longa extract protects against gastric ulcers by blocking H2 histamine receptors. Biol Pharm Bull. 2005;28(12):2220-4. https://doi.org/10.1248/bpb.28.2220

PMid:16327153

28. Tolman KG. Gastrointestinal and liver. In: Remington: The Science and Practice of Pharmacy. $2^{\text {nd }}$ ed. London: Lippincott Williams and Wilkins; 2000. p. 1219-20.

29. Tuorkey M, Karolin K. Anti-ulcer activity of curcumin on experimental gastric ulcer in rats and its effect on oxidative stress/antioxidant, IL-6 and enzyme activities. Biomed Environ Sci. 2009;22(6):488-95. https://doi.org/10.1016/ s0895-3988(10)60006-2

PMid:20337222 